\title{
NMR INVESTIGATION AND THEORETICAL CALCULATIONS OF THE EFFECT OF SOLVENT ON THE CONFORMATIONAL ANALYSIS OF 4',7-DI-HYDROXY-8-PRENYLFLAVAN
}

\author{
Antônio Flávio de Carvalho Alcântara*, Ana Frazão Teixeira and Izelene Felício da Silva \\ Departamento de Química, Instituto de Ciências Exatas, Universidade Federal do Amazonas, \\ Av. Gal. Rodrigo Otávio Jordão Ramos, 3000, 69077-000 Manaus - AM \\ Wagner Batista de Almeida and Dorila Piló-Veloso \\ Departamento de Química, Instituto de Ciências Exatas, Universidade Federal de Minas Gerais, \\ Av. Pres. Antônio Carlos, 6627, 31260-901 Belo Horizonte - MG
}

Recebido em 12/2/03; aceito em 10/11/03

\begin{abstract}
NMR INVESTIGATION AND THEORETICAL CALCULATIONS OF THE EFFECT OF SOLVENT ON THE CONFORMATIONAL ANALYSIS OF 4',7-DI-HYDROXY-8-PRENYLFLAVAN. The NMR conformational study of 4',7-di-hydroxy-8prenylflavan 1 was carried out in acetone- $d 6$, DMSO- $d 6$ and $\mathrm{CDCl}_{3}$ which enabled the proposition of three conformations, namely $\mathbf{1 a}, \mathbf{1 b}$ and 1c, differing in the position of the prenyl group. Geometry optimizations performed using AM1 method showed that 1a $\left(\Delta H_{\mathrm{f}}=-86.2 \mathrm{kcal} / \mathrm{mol}\right)$ is as stable as $\mathbf{1 b}\left(\Delta H_{\mathrm{f}}=-85.1 \mathrm{kcal} / \mathrm{mol}\right)$ and $\mathbf{1 c}\left(\Delta H_{\mathrm{f}}=-85.4 \mathrm{kcal} / \mathrm{mol}\right)$. When the solvent was included, the calculations showed that the solute-solvent interactions could be explained either in the light of the electronic intermolecular delocalization or the electrostatic character between solute and solvent. Theoretical calculations (HF/6-31G*, DFT/BLYP/6-31G*, and DFT/B3LYP/6-31G*) showed that the combination of these types of interactions present in each solute-solvent system, dependent on the chemical properties of the solvent, lead to different spatial arrangements of the prenyl group, which in turn determined the conformation of $\mathbf{1}$.
\end{abstract}

Keywords: Brosimum acutifolium; conformational analysis by NMR; theoretical calculations of di-hydroxyprenylflavan.

\section{INTRODUCTION}

Flavans are natural products belonging to the flavonoid class. They are very important from the biological viewpoint, presenting anti-oxidant, antibacterial, antitumoral and anti-HIV activities ${ }^{1-3}$. These substances are found in complex mixtures mainly because of the fact they condense with proteins and sugars. They suffer autocondensation or thermal decomposition, affording the formation of both oligomeric procyanidins and condensed and hydrolysable tanines ${ }^{4,5}$. As a result, despite the extensive occurrence of flavans in the vegetal kingdom, their phytochemical isolation is currently difficult ${ }^{6}$.

Brosimum acutifolium, a vegetal species found in the high lands of the Amazon region is largely used in folk medicine for the treatment of rheumatism ${ }^{7}$. Its extracts present protein-quinase inhibitory activities $^{8,9}$. The phytochemical study of the extract gave 4',7-dihydroxy-8-prenylflavan 1 (Figure 1) ) $^{10-12}$. The NMR study of this flavan presented varying results depending on whether the spectra were obtained in $\mathrm{CDCl}_{3}$ or DMSO- $d 6$. The current paper describes an attempt to verify whether this behavior is a result of conformational variations. The literature has described interesting conformational studies utilizing NMR experiments ${ }^{13}$. With this fact in mind, the conformational analysis of 1 by NMR using acetone- $d 6$, DMSO- $d 6$ and $\mathrm{CDCl}_{3}$ as solvents is presented. Based on results of these conformational analyses, the geometry optimization of the different proposed solvent conformations was performed by quantum chemical methods, as well as the theoretical calculations of both chemical properties and solvent effects on the conformations of $\mathbf{1}$.

*e-mail: aalcantara@ufam.edu.br

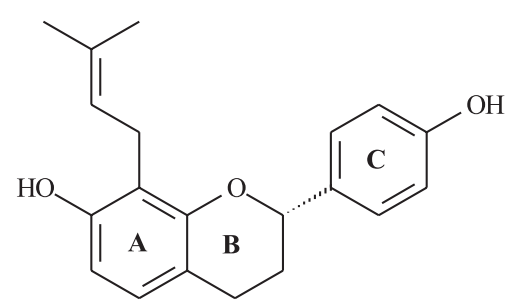

Figure 1. 4',7-di-hydroxy-8-prenylflavan 1, flavan isolated from B. acutifolium

\section{EXPERIMENTAL PART}

${ }^{1} \mathrm{H}$ and ${ }^{13} \mathrm{C}$ NMR spectra, and NOESY contour maps were recorded on a Bruker DRX 400 AVANCE, in acetone-d6, DMSO-d6 and $\mathrm{CDCl}_{3}$, without sample degasification. The chemical shifts were recorded in $\operatorname{ppm}(\delta$ units) in relation to TMS as an internal standard. Pulse conditions were as follows: for ${ }^{1} \mathrm{H}$ NMR, dwell time (DW) $149.600 \mu \mathrm{s}$, acquisition time (AQ) $3.985 \mathrm{~s}$, number of transients (NS) 16 , recycle delay (RD) $1.000 \mathrm{~s}$; for ${ }^{13} \mathrm{C}$ NMR spectra, DW $31.400 \mu \mathrm{s}$, AQ $2.058 \mathrm{~s}$, NS 1024, RD $2.000 \mathrm{~s}$, decoupling multiple resonance method Waltz-16; and for the NOESY contour maps, DW $113.600 \mu \mathrm{s}$, AQ $0.233 \mathrm{~s}$, NS 16, RD $2.000 \mathrm{~s}$, mixing time $200 \mathrm{~ms}$, time evolution $3 \mu \mathrm{s}$, TD $2048\left(\mathrm{~F}_{2}\right)$ and $512\left(\mathrm{~F}_{1}\right)$.

The methodology used in the isolation and determination of the physical and chemical data of $\mathbf{1}$, including $\mathrm{NMR}$ data for $\mathrm{CDCl}_{3}$ and DMSO- $d 6$, was described elsewhere ${ }^{10}$. For 1 in acetone- $d 6,{ }^{1} \mathrm{H}$ NMR (400 MHz) $\delta: ~ 8.29$ [s, HO(C-4')], 7.89 [s, HO(C-7)], 7.30 (d, J=8.36 Hz, H-2'/6'), 6.85 (d, J=8.36 Hz, H-3'/5'), 6.69 (dd, $J=7.86$ and $0.98 \mathrm{~Hz}, \mathrm{H}-5), 6.38$ (d, $J=7.86 \mathrm{~Hz}, \mathrm{H}-6$ ), 5.27 (tqq, $J=7.43,1.49$ and $1.05 \mathrm{~Hz}, \mathrm{H}-2$ "), 4.97 (dd, J=9.74 and $2.41 \mathrm{~Hz}, \mathrm{H}-2$ ), 3.34 (ddl, 
$J=13.53$ and $7.43 \mathrm{~Hz}, \mathrm{H}-1$ "a), 3.29 (ddl, $J=13.53$ and $7.43 \mathrm{~Hz}, \mathrm{H}-$ 1"b), 2.86 (dddd, $J=15.93,10.73,5.70$ and $0.98 \mathrm{~Hz}, \mathrm{H}-4_{\mathrm{ax}}$ ), 2.66 (ddd, $J=15.93,5.32$ and $3.42 \mathrm{~Hz}, \mathrm{H}-4$ ) ) 2.13 (dddd, $J=13.24,5.70$, 3.42 and $2.41 \mathrm{~Hz}, \mathrm{H}-3_{\mathrm{eq}}$ ) 1.93 (dddd, $J=13.24,10.73,9.74$ and 5.32 $\mathrm{Hz}, \mathrm{H}-3_{\mathrm{ax}}$ ), 1.63 (dl, $J=1.05 \mathrm{~Hz}, \mathrm{H}-5$ ") and 1.61 (dl, $J=1.49 \mathrm{~Hz}, \mathrm{H}-$ 4 "); ${ }^{13} \mathrm{C}$ NMR (100 MHz) $\delta: 157.82$ (C-4'), 154.77 (C-7), 154.54 (C-9), 134.39 (C-1'), 130.62 (C-3”), 128.16 (C-2'/6'), 127.54 (C5), 124.51 (C-2”), 116.28 (C-8), 115.97 (C-3'/5'), 113.86 (C-10), 108.41 (C-6), 78.29 (C-2), 31.02 (C-3), 26.02 (C-4”), 25.53 (C-4), 23.10 (C-1") and 18.05 (C-5").

Theoretical studies were carried out using the software packages SPARTAN, TITAN and GAUSSIAN ${ }^{14}$. Spatial arrangements of $\mathbf{1}$, determined through NOESY experiments in different solvents, were used as initial models for geometry optimization calculations in the vapour phase. Geometry optimization was performed using the semiempirical method AM $1^{15}$ and the Density Functional Theory (DTF) ${ }^{16}$ method with functionals BLYP ${ }^{17,18}$ and $\mathrm{B}^{2} \mathrm{LYP}^{19-22}$ using a 6-31G*23-27 basis set (respectively, DFT/BLYP/6-31G* and DFT/B3LYP/6$\left.31 \mathrm{G}^{*}\right)$. The structures obtained by theoretical calculations were characterized as true energy minima in PES through frequency calculations (when the frequencies are real, it corresponds to a structure of true minimal energy).

The rotational barriers of the C-8 - C-1", C-1" - C-2" and C-2 $\mathrm{C}-1$ ' bonds were calculated by varying the dihedral angles determined, respectively, by C-7,C-8,C-1",C-2" $(\alpha)$; by C-8,C-1",C-2",H-2" $(\beta)$ and by $\mathrm{C}-3, \mathrm{C}-2, \mathrm{C}-1$ ', C-2'. For each angular variation between 4 and 5 degrees, geometry optimization was performed by using the semiempirical method AM1, keeping only those atoms that determine the dihedral angle fixed.

The calculations of the atomic contributions of the occupied molecular orbitals (MO's) of the optimized geometries were also performed at the DFT/BLYP/6-31G* and DFT/B3LYP/6-31G* levels, for the structures in the vapour phase state, after geometry optimization in the same level of calculation.

Geometry optimization calculations of the solute-solvent systems were performed using the semi-empirical method AM1. The enthalpies of the solute-solvent interactions were calculated by the combination of the formation enthalpies of each solute-solvent system with those calculated separately for the corresponding conformers and solvents.

Calculations of solvent effects were also performed for HF/321G* fully optimized geometries, using the Polarizable Continuum Model (PCM) at the HF/6-31G** level ${ }^{28,29}$. In these cases, the electronic-nuclear $\left(E_{\text {ele-nuc }}\right)$ and solvation $\left(E_{\text {solv }}\right)$ energies were obtained.

\section{RESULTS AND DISCUSSION}

At first, the ${ }^{1} \mathrm{H}$ NMR signals of the prenyl group of $\mathbf{1}$ were analyzed. Differently from that reported for spectra obtained in $\mathrm{CDCl}_{3}$ and DMSO- $d 6^{10-12}$, the magnetic non-equivalence of the two geminal hydrogens $\mathrm{H}-1$ " was made explicit in acetone- $d 6$. The signals at $\delta_{\mathrm{H}}$ 3.34 (H-1"a) and 3.29 (H-1"b), making up the AB portion of an ABX system with geminal coupling ${ }^{2} J_{\mathrm{H}, \mathrm{H}}=13.53 \mathrm{~Hz}$ and the coupling of these two hydrogens with $\mathrm{H}-2$ ", ${ }^{3} J_{\mathrm{H}, \mathrm{H}}=7.43 \mathrm{~Hz}$, were observed. NOESY data of $\mathbf{1}$ in acetone- $d 6$ presented in Table 1 show that $\mathrm{H}-$ 1 "'a is closer to $\mathrm{HO}(\mathrm{C}-7)$, while $\mathrm{H}-1$ '”b is closer to $\mathrm{H}-2$ ' /6'. In addition, correlations of H-2", H-4" or H-5" with the hydrogens of the C ring were not observed. These results indicate that, in the plane of the A and $\mathrm{B}$ rings, the isobutylenic part of the prenyl ramification is in anti conformation to the $\mathrm{C}$ ring. In addition, the absence of correlations of $\mathrm{H}-2$ " with $\mathrm{HO}(\mathrm{C}-7)$ and $\mathrm{H}-2$ indicates that the prenyl ramification is on a plane perpendicular to the A ring. This is in agreement with the conformation in which both $\mathrm{H}-1$ " are syn to the $\mathrm{C}$ ring (1a in Figure 2).

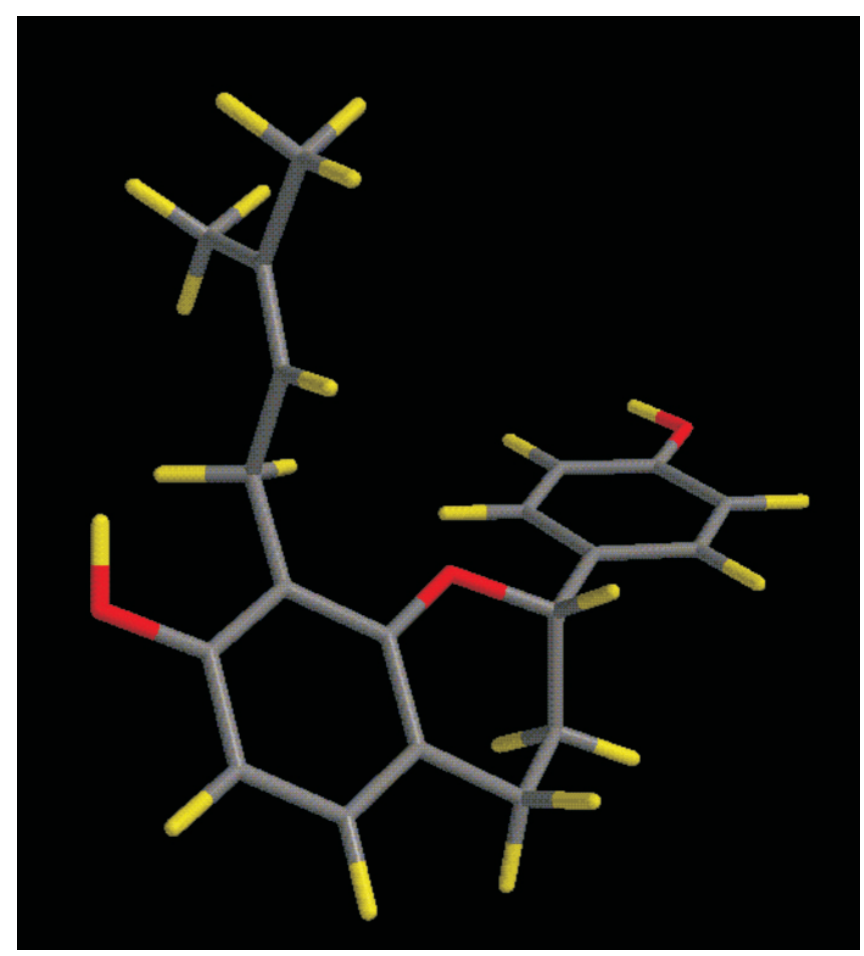

Figure 2. Conformer 1a, geometry optimization (BLYP/6-31G*) from conformational analysis by NMR of 1 in acetone-d6 (hydrogen in yellow, carbon in grey and oxygen in red)

Next, the hydrogen signals of the $\mathrm{B}$ and $\mathrm{C}$ rings of $\mathbf{1}$ in acetone$d 6$ were analyzed. Table 1 presents the NOESY correlations of $\mathrm{H}-2$ with $\mathrm{H}-4_{\mathrm{ax}}, \mathrm{H}-3_{\mathrm{eq}}$ and $\mathrm{H}-2$ '/6', indicating that $\mathrm{H}-2$ must be in an axial position and, therefore, the $\mathrm{C}$ ring is in an equatorial position. The axial position of $\mathrm{H}-2$ can be confirmed both by the NOESY correlation of $\mathrm{H}-2$ '/6' with $\mathrm{H}-3$ ax and by ${ }^{1} \mathrm{H}$ NMR, through the ${ }^{3} J_{\mathrm{H}-2, \mathrm{H}-3 \mathrm{ax}}=9.74$ $\mathrm{Hz}$ and ${ }^{3} J_{\mathrm{H}-2, \mathrm{H}-3 \mathrm{eq}}=2.41 \mathrm{~Hz}$ coupling constants, characteristic of diaxial relations between $\mathrm{H}-2$ and $\mathrm{H}-3_{\text {ax }}$ and axial-equatorial relations between $\mathrm{H}-2$ and $\mathrm{H}-3$ eq, respectively.

The NOESY data of $\mathbf{1}$ in DMSO- $d 6$ presented in Table 1 show that, differently from that observed in the acetone- $d 6$ experiment, $\mathrm{H}$ 2'/6' correlates with H-5", but not with H-1". This observation indicates that the isobutylene portion of the prenyl ramification and the $\mathrm{C}$ ring must be syn in relation to the plane of the $\mathrm{A}$ and $\mathrm{B}$ rings (1b in Figure 3). The correlation of $\mathrm{HO}(\mathrm{C}-7)$ with $\mathrm{H}-2$ ", but not with $\mathrm{H}-1$ " is also observed in this table. This fact allows one to infer that the prenyl group of $\mathbf{1 b}$ suffers a rotation close to 180 degrees around the C-8 - C-1" bond, in relation to 1a. In contrast, H-2 presents equivalent correlations in the NOESY experiment both in DMSO$d 6$ and acetone- $d 6$. This result indicates that $\mathbf{1 a}$ and $\mathbf{1 b}$ present the same conformation for the $\mathrm{B}$ ring, in which the $\mathrm{C}$ ring is in the equatorial position.

The correlation between $\mathrm{H}-2$ and $\mathrm{H}-5$ " is observed in the NOESY data of $\mathbf{1}$ in $\mathrm{CDCl}_{3}$ presented in Table 1. This correlation indicates that $\mathrm{H}-2$ and the isobutylene portion of the prenyl ramification are on the same side of the plane of the A and B rings. Therefore, the prenyl ramification and the $\mathrm{C}$ ring are anti (1c in Figure 4) to each other. Considering the correlations of $\mathrm{H}-1$ " with $\mathrm{H}-2$ '/6' and $\mathrm{H}-2$, it can be established that at least one of the H-1" hydrogens is close to the $\mathrm{C}$ ring. Furthermore, the absence of correlations of $\mathrm{H}-3_{\text {ax }}\left(\delta_{\mathrm{H}}\right.$ 
Table 1. NOESY data of $\mathbf{1}$ in acetone- $d 6$, DMSO- $d 6$ and $\mathrm{CDCl}_{3}$, it is not decreved correlations between geminal hydrogens

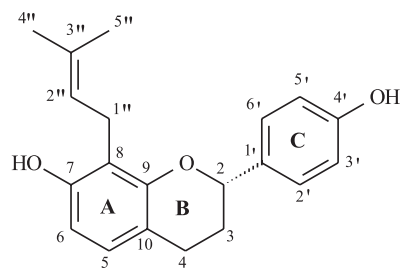

\begin{tabular}{|c|c|c|c|}
\hline Hydrogen & acetone- $d 6$ & DMSO- $d 6$ & $\mathrm{CDCl}_{3}$ \\
\hline 2 & $3_{\mathrm{eq}} ; 4_{\mathrm{ax}} ; 2^{\prime} / 6^{\prime}$ & $3_{\mathrm{eq}} ; 4_{\mathrm{ax}} ; 2^{\prime} / 6^{\prime}$ & $\begin{array}{l}5 " ; 3_{\mathrm{eq}} ; 4_{\mathrm{eq}} ; 4_{\mathrm{ax}} ; \\
1^{\prime \prime} ; 2^{\prime} / 6\end{array}$ \\
\hline $3_{\mathrm{ax}}$ & $4_{\mathrm{eq}} ; 4_{\mathrm{ax}} ; 2^{\prime} / 6$ & $4_{\mathrm{eq}} ; 4_{\mathrm{ax}}$ & $3_{\mathrm{eq}} ; 4_{\mathrm{eq}} ; 2^{\prime} / 6^{\prime}$ \\
\hline $3_{\text {eq }}$ & $4_{\mathrm{eq}} ; 4_{\mathrm{ax}} ; 2$ & $\begin{array}{l}4_{\mathrm{eq}} ; 4_{\mathrm{ax}} ; 2 ; \\
2^{\prime} / 6\end{array}$ & $3_{\mathrm{ax}} ; 4_{\mathrm{ax}} ; 4_{\mathrm{eq}} ; 2 ; 2^{\prime} / 6^{\prime}$ \\
\hline $4_{\text {eq }}$ & $3_{\mathrm{eq}} ; 3_{\mathrm{ax}} ; 5$ & $3_{\mathrm{ax}} ; 3_{\mathrm{eq}} ; 2 ; 5$ & $3_{\mathrm{ax}} ; \mathrm{H}-3_{\mathrm{eq}} ; 4_{\mathrm{ax}} ; 2 ; 5$ \\
\hline $4_{a x}$ & $3_{\mathrm{eq}} ; 3_{\mathrm{ax}} ; 2 ; 5$ & $3_{\mathrm{ax}} ; 3_{\mathrm{eq}} ; 5$ & $3_{\mathrm{eq}} ; 4_{\mathrm{eq}} ; 2 ; 5$ \\
\hline 5 & $4_{\mathrm{eq}} ; 4_{\mathrm{ax}} ; 6$ & $4_{\mathrm{eq}} ; 4_{\mathrm{ax}} ; 6$ & $4_{\mathrm{eq}} ; 4_{\mathrm{ax}} ; 6$ \\
\hline 6 & $5 ; \mathrm{HO}(\mathrm{C}-7)$ & $5 ; \mathrm{HO}(\mathrm{C}-7)$ & 5 \\
\hline $2^{\prime} / 6{ }^{\prime}$ & $3_{\mathrm{ax}} ; 1^{\prime \prime} ; 2 ; 3^{\prime} / 5^{\prime}$ & $5 " ; 3_{\mathrm{eq}} ; 2 ; 3^{\prime} / 5^{\prime}$ & $3_{\mathrm{ax}} ; 3_{\mathrm{eq}} ; 1^{\prime \prime} ; 2 ; 3^{\prime} / 5$ \\
\hline $3^{\prime} / 5$ & $2^{\prime} / 6^{\prime} ; \mathrm{HO}\left(\mathrm{C}-4^{\prime}\right)$ & $\begin{array}{l}5^{\prime \prime} ; 2^{\prime} / 6^{\prime} ; \\
\mathrm{HO}\left(\mathrm{C}-4^{\prime}\right)\end{array}$ & $2^{\prime} / 6^{\prime}$ \\
\hline 1 "a & 5"; $\mathrm{HO}(\mathrm{C}-7)$ & $5 " ; 2 "$ & 5"; 2; 2"; 2'/6' \\
\hline $1 " b$ & $2 " ; 2^{\prime} / 6^{\prime}$ & & \\
\hline $2 "$ & $4 " ; 1 "$ & $\begin{array}{l}\text { 4"; 1"; } \\
\mathrm{HO}(\mathrm{C}-7)\end{array}$ & 4"; 1" \\
\hline $4 "$ & $2 "$ & $2 "$ & $2 "$ \\
\hline $5 "$ & $1 "$ & $1^{\prime \prime} ; 3^{\prime} / 5^{\prime} ; 2^{\prime} / 6^{\prime}$ & $1 " ; \mathrm{H}-2$ \\
\hline $\mathrm{HO}(\mathrm{C}-7)$ & $1 " ; 6$ & $2 " ; 6$ & \\
\hline $\mathrm{HO}\left(\mathrm{C}-4^{\prime}\right)$ & $3^{\prime} / 5$ & $3^{\prime} / 5^{\prime}$ & \\
\hline
\end{tabular}

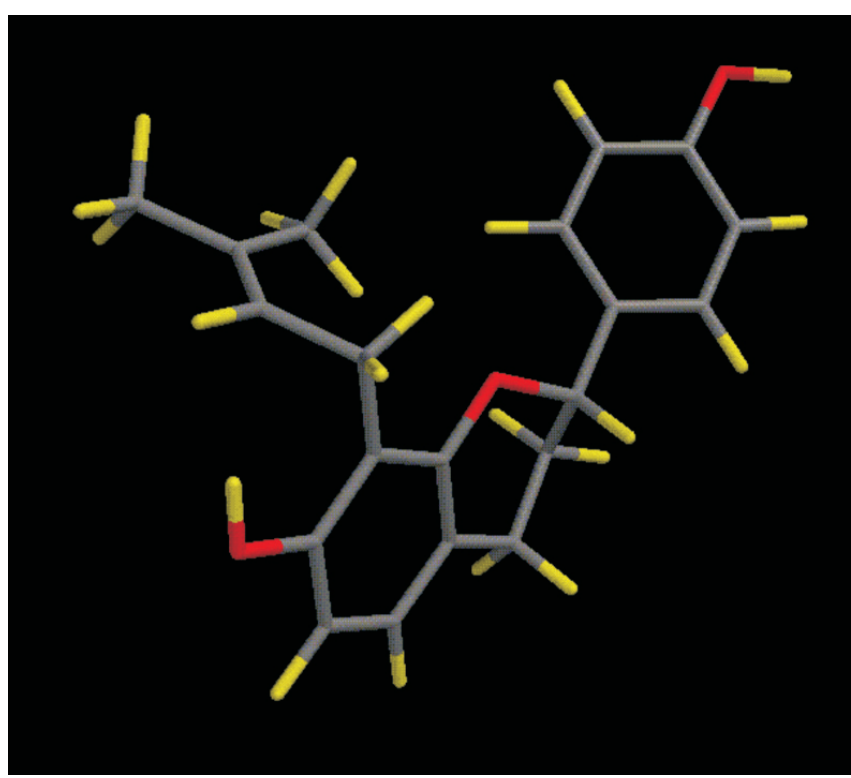

Figure 3. Conformer 1 b, geometry optimization (BLYP/6-31G*) from conformational analysis by NMR of $\mathbf{1}$ in DMSO-d6 (hydrogen in yellow, carbon in grey and oxygen in red)

1.98) with either $\mathrm{H}-2$ or $\mathrm{H}-4_{\mathrm{ax}}\left(\delta_{\mathrm{H}} 2.91\right)$ confirms that these three hydrogens are in alternating axial positions in the $\mathrm{B}$ ring.

The NMR conformational analysis of $\mathbf{1}$ demonstrated a

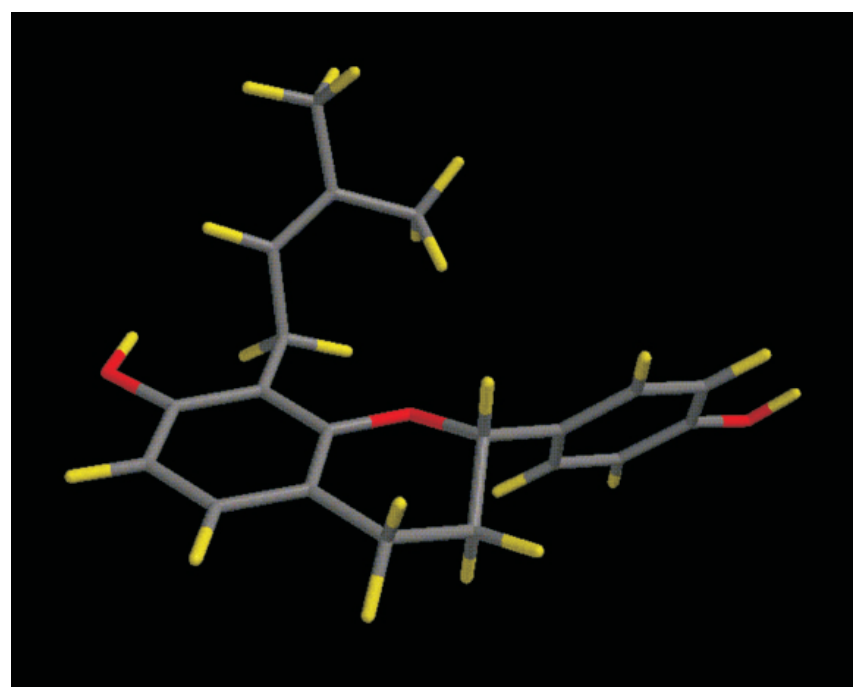

Figure 4. Conformer 1c, geometry optimization (BLYP/6-31G*) from conformational analysis by NMR of $\mathbf{1}$ in $\mathrm{CDCl}_{3}$ (hydrogen in yellow, carbon in grey and oxygen in red)

relationship between the solvent and the spatial position of the prenyl group. However, independently of the solvent used, the $\mathrm{C}$ ring is in an equatorial position in all the conformations. Nevertheless, the geometry optimization of $\mathbf{1 a}, \mathbf{1 b}$ and $\mathbf{1 c}$, presenting an equatorial $\mathrm{C}$ ring, as well as the respective conformations presenting an axial $\mathrm{C}$ ring were calculated (DFT/BLYP/6-31G*) for comparison purposes. The conformations with the equatorial $\mathrm{C}$ ring are about $0.6 \mathrm{kcal} / \mathrm{mol}$ more stable. Despite this small difference in energy, only conformers with an equatorial $\mathrm{C}$ ring are detected by NMR, signals indicative of conformational interconversion in the B ring not being observed. In contrast, calculations using the AM1 method show different rotational barriers of the interannular bond $\left(\mathrm{C}-2-\mathrm{C}-1^{\prime}\right)$, being $2.9 \mathrm{kcal} / \mathrm{mol}$ when the $\mathrm{C}$ ring is axial, and $0.4 \mathrm{kcal} / \mathrm{mol}$ when it is equatorial. In the latter case, the smaller potential energy for the rotation of the interannular bond contributes to the thermodynamic stability of the conformation. It should be noted that the AM1 barriers have to be looked at with care ${ }^{30}$, and the rotational barriers discussed above should be viewed as estimates.

In the vapour phase and no considering intermolecular interactions, the enthalpies of formation of conformers $\mathbf{1 a}, \mathbf{1 b}$ and 1c were calculated (AM1) to obtain $\Delta H_{\mathrm{f}}=-86.2,-85.1$ and -85.4 $\mathrm{kcal} / \mathrm{mol}$, respectively. Considering that these values are close, three conformations for each solvent could occur, but were not observed by NMR. This fact suggests the possibility of contribution of the solute-solvent interaction, that favors a particular conformation and a high energy barrier for conformational interconversion ${ }^{31}$. According to literature, under the experimental conditions of the ${ }^{1} \mathrm{H} \mathrm{NMR}$, the energy barrier for the coalescence of the signals should be superior to $10 \mathrm{kcal} / \mathrm{mol}^{32}$. Taking this fact into account, the rotational barriers involving C-8 - C-1" and C-1" - C-2" of the prenyl group were calculated by the AM1 method to give the results presented in Figure 5 .

Rotational barriers equal to 7.8 and $7.5 \mathrm{kcal} / \mathrm{mol}$ were calculated for C-8 - C-1" bonds, respectively, with $\alpha$ dihedral angles determined for C-7,C-8,C-1",C-2" around 0 and 180 degrees. These energy values indicate restrictions for the free rotation of this bond ${ }^{33}$. The $\alpha$ values calculated for the optimized structures are 101.1 degrees in 1a, 268.3 degrees in $\mathbf{1 b}$, and 76.7 degrees in 1c. As the analysis of Figure 5 suggests, these values of $\alpha$ indicate that $\mathbf{1 a}$ and $\mathbf{1 c}$ are in different intervals of the minimal energy regions in relation to $\mathbf{1 b}$. Taking into 

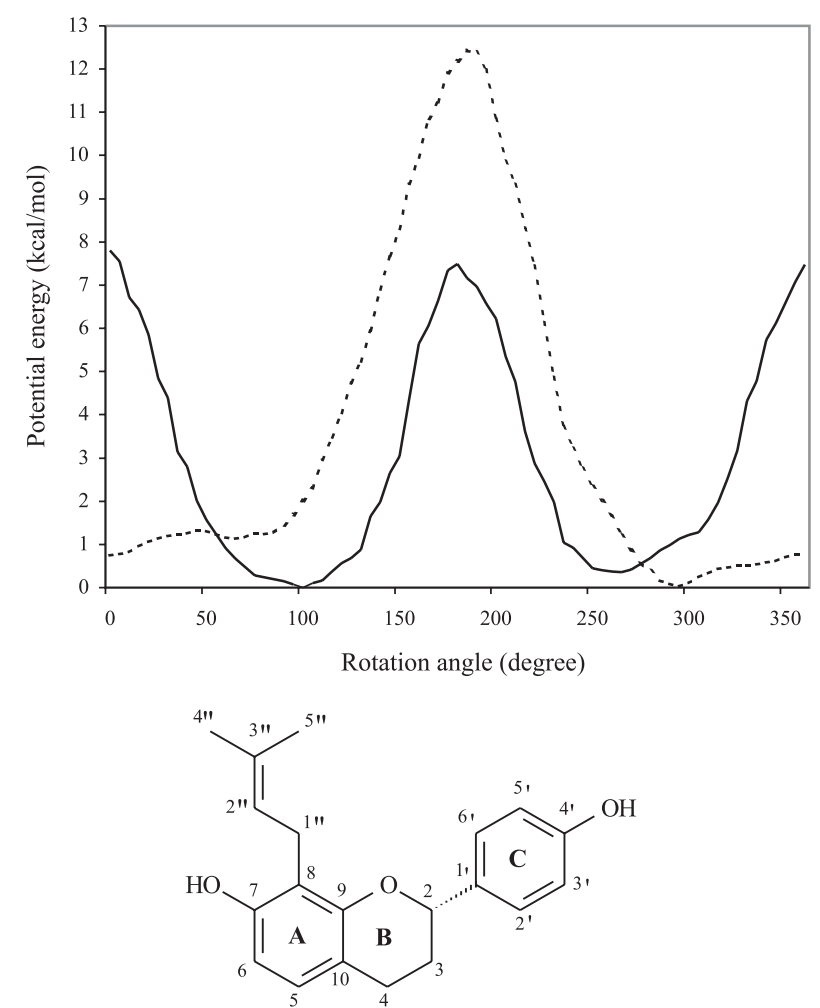

Figure 5. Potential energy calculation (AM1) of rotation of the C-8 $-C-1$ ", ( $\alpha$, continuous line, determinated by C-7,C-8,C-1",C-2") and C-1" $-C-2$ " ( $\beta$, dashed line, determinated by $C-8, C-1$ ", $C-2$ ", $H-2$ ") bonds in flavan 1

account only the results of these calculations, energy restriction for the interconversion between $\mathbf{1 a}$ and $\mathbf{1 c}$, considering only the pseudorotations of bond C-8 - C-1", would not be expected. However, the same can not be proposed for the interconversions of these conformers in $\mathbf{1 b}$, which is in the other minimal region of the potential energy curve.

The calculation of the rotational barrier of bond C-1" - C-2" results in only one energy maximum of $12.4 \mathrm{kcal} / \mathrm{mol}$ for the $\beta$ dihedral angles, determined for C-8,C-1",C-2",H-2" equal to 182.6 degrees. This energy barrier does not favor the free rotation of the bond. The $\beta$ values calculated for the optimized structures of $\mathbf{1}$ in different solvents are 66.3 degrees for $\mathbf{1 a}, 61.6$ degrees for $\mathbf{1 b}$, and 295.1 degrees for 1c. Independently of these values, the existence of only one energy maximum for $\beta$ indicates that there would be no restriction for the interconversion of these three conformers.

The mixture of conformations derived from the interconversions inferred from theoretical calculations of the rotational barriers in relation to $\alpha$ and $\beta$ was not detected by NMR. Since these calculations do not take the participation of the solvent into account, one can conclude that the solute-solvent interactions have a significant contribution to the restriction of the conformational intervention. Unfortunately, the quantum chemical calculation of the rotational potential energy curve with the explicit inclusion of the solvent is not a feasible computational task.

To analyze the effect of the solvent on a given conformation, geometry optimizations were performed taking the interactions of each conformer 1a, $\mathbf{1 b}$, and 1c with each of the three solvents acetone, DMSO and $\mathrm{CHCl}_{3}$ - into account. Table 2 presents the results obtained by the AM1 method for formation $\left(\Delta H_{\mathrm{f}}\right)$ and interaction $\left(\Delta H_{\mathrm{i}}\right)$ enthalpies calculated for each of these solute-solvent systems. In these calculations, the geometry of each conformer was frozen so that only the effect of the solvent in its interactions with a certain
Table 2. Formation $\left(\Delta H_{\mathrm{f}}\right)$ and interaction $\left(\Delta H_{\mathrm{i}}\right)$ enthalpies calculated (AM1) for solute-solvent systems with frozen geometries of $\mathbf{1 a}, \mathbf{1 b}$ and $1 \mathbf{c}$ and the solvents were explicitly located close to A ring and to the prenyl group

\begin{tabular}{lcc}
\hline System & $\Delta H_{\mathrm{f}}(\mathrm{kcal} / \mathrm{mol})$ & $\Delta H_{\mathrm{i}}(\mathrm{kcal} / \mathrm{mol})$ \\
\hline 1a-acetone & -136.2 & -2.9 \\
1a-DMSO & -125.4 & -1.2 \\
1a-CHCl $_{3}$ & -113.7 & -0.1 \\
1b-acetone & -133.6 & -1.1 \\
1b-DMSO & -126.5 & -1.7 \\
1b-CHCl $_{3}$ & -113.3 & -1.2 \\
1c-acetone $_{\text {1c-DMSO }}$ & -134.4 & -0.9 \\
1c-CHCl $_{3}$ & -124.9 & -1.2 \\
\hline
\end{tabular}

conformation of $\mathbf{1}$ to $\Delta H_{\mathrm{f}}$ already calculated could be considered. In addition, the solvents were explicitly located close to the A ring and to the prenyl group. This choice of location of the solvent was made because the difference between the conformers $\mathbf{1 a}, \mathbf{1 b}$ and $\mathbf{1 c}$ involves fundamentally the spatial disposition of the prenyl group.

From the data in Table 2, it can be observed that in general the interaction enthalpy of each conformer with each of the three solvents is different, and also that the interactions are more thermodynamically favored for 1a with acetone $\left(\Delta H_{\mathrm{i}}=-2.8 \mathrm{kcal} / \mathrm{mol}\right), \mathbf{1 b}$ with DMSO $\left(\Delta H_{\mathrm{i}}=-1.7 \mathrm{kcal} / \mathrm{mol}\right)$ and $1 \mathrm{c}$ with $\mathrm{CHCl}_{3}\left(\Delta H_{\mathrm{i}}=-2.7 \mathrm{kcal} / \mathrm{mol}\right)$. These results confirm the existence of a preference for a given conformation for each solvent. This observation is in agreement with NMR experimental observations.

Calculations (DFT/BLYP/6-31G* and DFT/B3LYP/6-31G*) of the atomic contributions related to MO's of conformers $\mathbf{1 a}, \mathbf{1 b}$, and 1c were realized with the objective of investigating the nature of the solute-solvent interaction. By DFT/BLYP/6-31G*, the electronic density $\left(c^{2}\right.$, where $c$ is the contribution of the atomic orbital to a given MO) of orbitals of the carbons of the A ring to HOMO is 0.392 in 1a, 0.359 in $\mathbf{1 b}$ and 0.408 in 1c. By DFT/B3LYP/6-31G*, the values of $c^{2}$ are $0.609,0.465$, and 0.598 , respectively. In both calculations, similar behaviors were observed in which the carbons of the A ring contribute predominately to the HOMO of the three conformers, as well as a smaller contribution relative to the carbons of this ring in $\mathbf{1 b}$.

Considering that the HOMO must be the most relevant for the intermolecular interactions, ring A of $\mathbf{1}$ was initially chosen as a reference for the study of the solute-solvent interaction. Thus, AM1 optimization of the conformers were performed with frozen geometries, explicitly locating the solvent close to the A ring and on the side opposite to the prenyl group to dismiss effects other than the interaction of the solvent with this ring. For the optimized geometries (AM1) of the $\mathbf{1 a}$-acetone, $\mathbf{1 b}$-DMSO and $\mathbf{1} \mathbf{c}-\mathrm{CHCl}_{3}$ systems with solvent explicitly close to the A ring, the formation enthalpies were $-136.5,-125.5$ and $-114.3 \mathrm{kcal} / \mathrm{mol}$, respectively. From these results, the enthalpy of the solute-solvent interaction $\left(\Delta H_{i}\right)$ could be estimated to be equal to $-2.5,-1.4$, and $-1.0 \mathrm{kcal} / \mathrm{mol}$, respectively. These results show that the A ring and solvent interactions are thermodynamically more favored in $\mathbf{1 a}$-acetone than in $\mathbf{1 b}$-DMSO, wich, in turn, is more favored than in $\mathbf{1 c}-\mathrm{CHCl}_{3}$.

Calculations (DFT/BLYP/6-31G* and DFT/B3LYP/6-31G*) of the atomic contributions for MO's of these systems were performed to study the kind of interactions of the A ring of each conformer with the corresponding solvent. In general, the comparison to those contributions obtained for conformers treated in isolation, in all solutesolvent systems studied reveals that the carbons of ring A have a 
larger number of occupied MO's and consequently, smaller electronic density $\left(c^{2}\right)$ values per orbital. In the 1a-acetone system, the most significant contributions of the carbons of ring A are in HOMO, HOMO-1, HOMO-2, HOMO-3, and HOMO-4; in 1b-DMSO system, the contributions are in HOMO-1, HOMO-2, HOMO-3, and HOMO4; and in $1 \mathrm{c}-\mathrm{CHCl}_{3}$ system, in HOMO, HOMO-1, HOMO-3, and HOMO-4. These results show the electronic changes when the contributions of the carbons in ring A for occupied frontier MO's of conformers treated in isolation are compared to the same conformers in systems also containing the solvent. Thus, the interactions of the solute A ring with the solvent significantly influence the electronic properties of conformer $\mathbf{1}$.

Furthermore, these calculations show that HOMO and HOMO1 present concomitant contributions of solute and solvent atoms in the 1a-acetone system, as shown in Figure 6. This fact indicates that the intermolecular interactions involve electronic delocalization with the joint participation of atoms of the solute and solvent in these systems. Similar results were observed for the 1b-DMSO system. However, in this case, concomitant contribution of atoms of $\mathbf{1 b}$ and solvent only for HOMO-4 of the 1b-DMSO system is observed. The observation that this orbital is significantly more stable than those MO's of the 1a-acetone system which present electronic
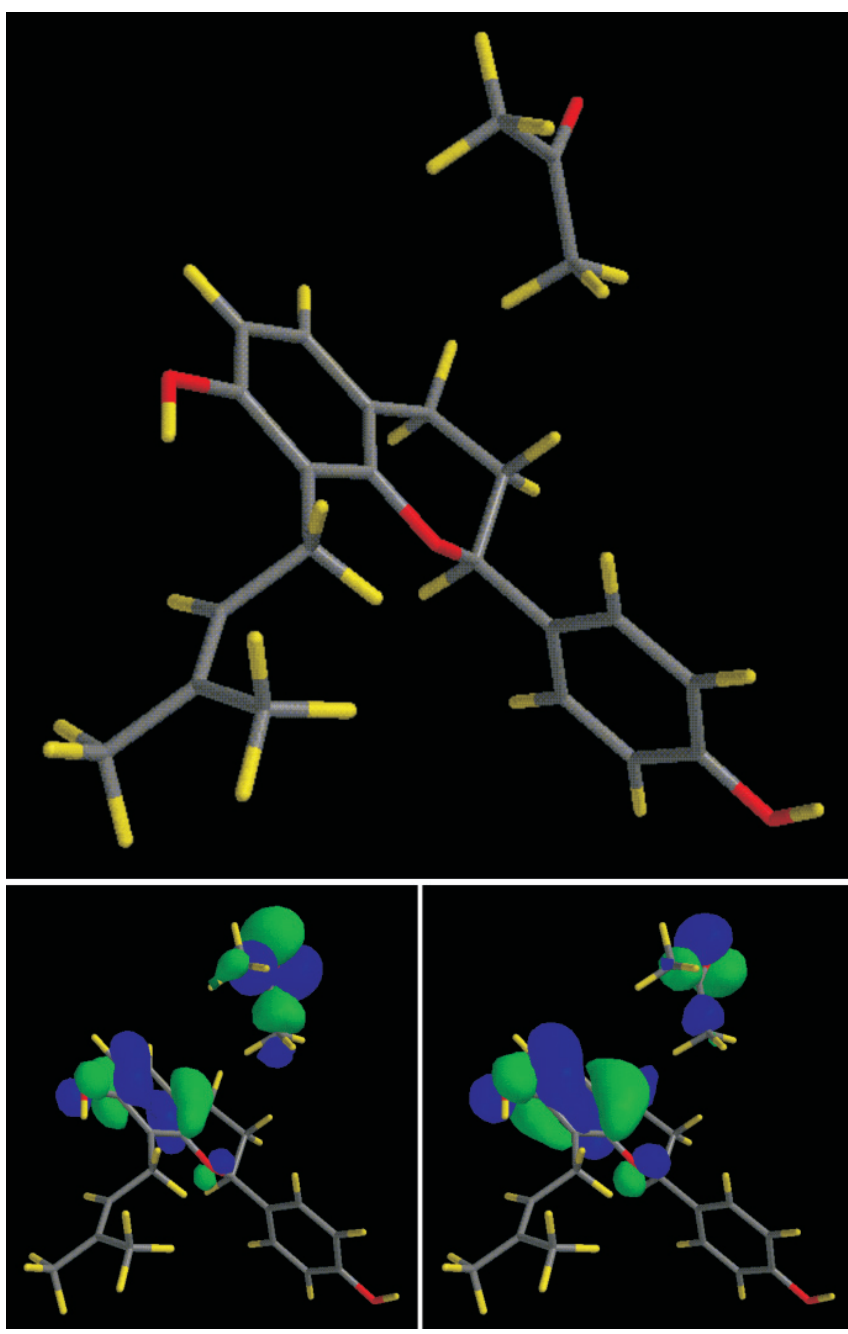

Figure 6. Optimized geometry (B3LYP/6-31G*) of 1a-acetone system, considering interactions between ring A and solvent (superior structure) and inferior structures, of left side to right side, HOMO and HOMO-1 of this system (hydrogen in yellow, carbon in grey and oxygen in red; positive phases in green and negative phases in blue) delocalization between solute and solvent suggests that the interactions of the A ring of $\mathbf{1}$ with the solvent are relatively less intense in the 1b-DMSO system. In contrast, none of the occupied MO's studied in the $1 \mathbf{c}-\mathrm{CHCl}_{3}$ system presented concomitant contributions of solvent and solute atoms. Therefore, the interactions of the solvent with ring A have a predominantly electrostatic character in the $1 \mathrm{c}-\mathrm{CHCl}_{3}$ system.

AM1 calculations demonstrate that the dipole moment of $1 \mathbf{c}(\mu=$ $2.88 \mathrm{D})$ is larger than that of $\mathbf{1 a}(\mu=1.32 \mathrm{D})$, and of $\mathbf{1 b}(\mu=2.49 \mathrm{D})$. This factor could be contributing to favor an electrostatic interaction with $\mathrm{CHCl}_{3}$. However, the calculated DFT (B3LYP/6-31G*) dipole moments are somehow different from the AM1 ones being $1 \mathbf{a}(\mu=$ $3.10 \mathrm{D}), \mathbf{1 b}(\mu=2.48 \mathrm{D})$ and $\mathbf{1 c}(\mu=2.73 \mathrm{D})$. From these results the effect of the dipole moment on the electrostatic solute-solvent interactions can not be established (the acetone would be a candidate due to the higher dipole moment value of 1a at the DFT level). Calculations using a continuum model, PCM, were also carried out. Table 3 give the PCM solvation energies $\left(E_{\text {solv }}\right)$ for the three conformers of compound $\mathbf{1}$ in acetone, DMSO and $\mathrm{CHCl}_{3}$. For all solvents $E_{\text {solv }}$ is negative indicating the solvent effect of stabilizing each conformer. This effect is more pronounced in acetone, where, $E_{\text {solv }}=-5.3,-4.6$ and $-5.2 \mathrm{kcal} / \mathrm{mol}$, respectively for $\mathbf{1 a}, \mathbf{1 b}$ and $\mathbf{1 c}$. The results alone do not explain the NMR data, which show a conformational preference of $\mathbf{1 a}, \mathbf{1 b}$ and $\mathbf{1 c}$ in acetone, DMSO and $\mathrm{CHCl}_{3}$ respectively. Therefore, besides solute-solvent electrostatic interactions and dielectric constant of the solvent, regioespecificity must be considered to describe the solute-solvent interactions in order to explain the stability of the systems $\mathbf{1 a}$-acetone, $\mathbf{1 b}$-DMSO and 1c- $\mathrm{CHCl}_{3}$.

Table 3. Electronic plus nuclear repulsion energy in gas phase $\left(E_{\text {ele-nuc }}\right), \mathrm{HF} / 3-21 \mathrm{G}^{*}$ fully optimized geometry value, and solvation energy $\left(E_{\text {solv }}\right), \mathrm{HF} / 6-31 \mathrm{G}^{* *}$ single point value, for $\mathbf{1 a}, \mathbf{1 b}$ and $\mathbf{1 c}$ in acetone, DMSO and $\mathrm{CHCl}_{3}$, using the Polarizable Continuum Model (PCM)

\begin{tabular}{lcccc}
\hline Conformer & $\begin{array}{c}E_{\text {ele-nuc }} \\
\text { (in hartree) }\end{array}$ & Acetone $^{\mathrm{a}}$ & $\begin{array}{c}E_{\text {solv }}(\text { in } \mathrm{kcal} / \mathrm{mol}) \\
\mathrm{DMSO}^{\mathrm{b}}\end{array}$ & $\mathrm{CHCl}_{3}^{\mathrm{c}}$ \\
\hline $\mathbf{1 a}$ & -994.788851 & -5.3 & -3.5 & -1.8 \\
$\mathbf{1 b}$ & -994.784292 & -4.6 & -2.7 & -1.2 \\
$\mathbf{1 a}$ & -994.784811 & -5.2 & -3.2 & -1.5 \\
\hline
\end{tabular}

(a) $\varepsilon=20.70$; (b) $\varepsilon=46.7$; (c) $\varepsilon=4.9$

Considering that conformers $\mathbf{1 a}, \mathbf{1 b}$ and $\mathbf{1 c}$ differ from each other in the spatial arrangement of the prenyl group in relation to the plane of the A ring (Figures 2 to 4), geometry AM1 optimizations were also carried out for the systems containing conformers with nonfrozen geometries, locating explicitly the solvent close to the prenyl group and the farthest possible from ring A to avoid the effect of this ring on the solute-solvent interactions. The enthalpies obtained were $-136.9,-126.4$, and $-114.7 \mathrm{kcal} / \mathrm{mol}$ respectively, for the geometries of 1a-acetone, $\mathbf{1 b}$-DMSO, and $\mathbf{1 c}-\mathrm{CHCl}_{3}$ systems, and the estimated $\Delta H_{\mathrm{i}}$ values were equal to $-4.4,-2.0$, and $-1.1 \mathrm{kcal} / \mathrm{mol}$, respectively. These results also show that the interactions of the prenyl group and the solvent are thermodynamically more favored in 1a-acetone than in $\mathbf{1 b}-\mathrm{DMSO}$, and in the latter more than in the $\mathbf{1 c}-\mathrm{CHCl}_{3}$ system.

In contrast, calculations (DFT/BLYP/6-31G* and DFT/B3LYP/ $6-31 \mathrm{G}^{*}$ ) of MO contributions for these systems displayed concomitant contributions of atoms of the prenyl group and solvent only in HOMO-3 and HOMO-4 of the 1b-DMSO system. In the remaining systems, concomitant contributions of atoms of the prenyl group and of the solvent were not observed. Therefore, one can 
propose that the interactions of this group with the solvent involve electronic delocalization only in the 1b-DMSO system, while in the two other systems, the interactions of the prenyl group with the solvents involve electrostatic interactions.

The solute-solvent interaction sites discussed above treated the A ring or prenyl group separately. Another geometry optimization calculation (AM1) was performed considering the possibilities for interaction of the solvent concomitantly with the prenyl group and the carbons and oxygen of ring A of each of the three conformers of 1. The results of these calculations showed that, for the 1a-acetone, 1b-DMSO, and 1c- $\mathrm{CHCl}_{3}$ systems, the enthalpies are -136.6, -128.0, and $-114.8 \mathrm{kcal} / \mathrm{mol}$, respectively, permitting estimation of $\Delta H_{\mathrm{i}}$ as $-3.2,-3.8$, and $-1.5 \mathrm{kcal} / \mathrm{mol}$, respectively. According to these results, the solute-solvent interaction is more favored thermodynamically in the 1b-DMSO system. Furthermore, differently from the 1a-acetone and $1 \mathrm{c}-\mathrm{CHCl}_{3}$ systems, the calculations (DFT/BLYP/6-31G* and DFT/B3LYP/6-31G*) of the MO's of 1b-DMSO demonstrate concomitant contributions of atoms of the solvent and of $\mathbf{1 b}$ (the prenyl group and hydroxyl group and carbons of the A ring) to HOMO, HOMO-1, and HOMO-2, as shown in Figure 7.

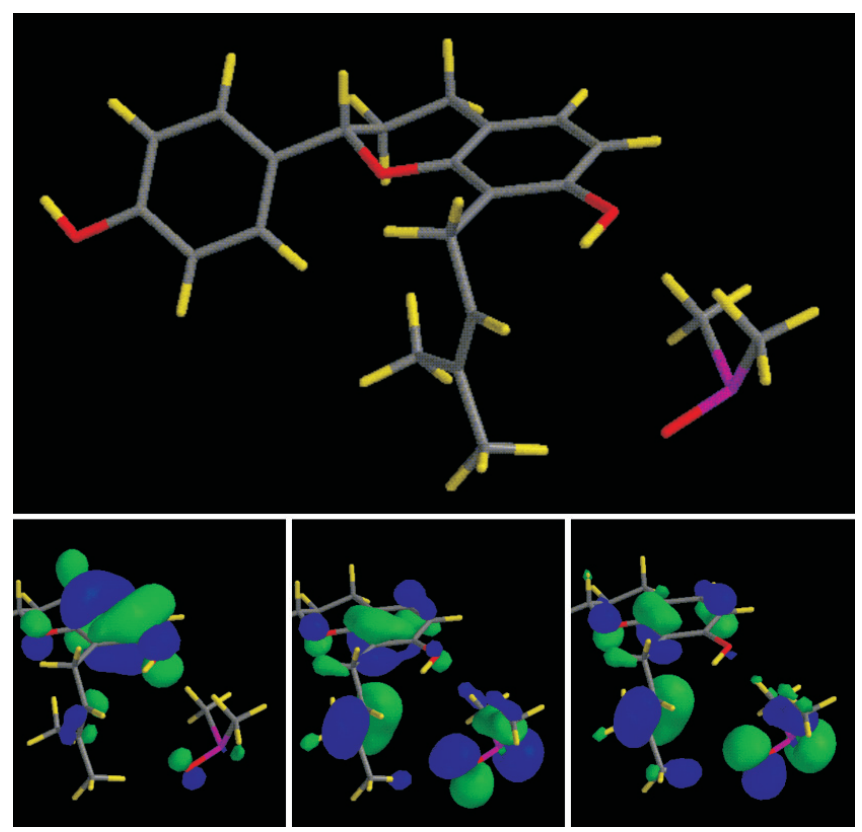

Figure 7. Optimized geometry (B3LYP/6-31G*) of $\mathbf{1 b}$-DMSO system, considering interactions of prenyl group, oxygen of ring A with solvent (superior structure) and inferior structures, of left side to right side, HOMO, HOMO-1 and HOMO-2 of this system (hydrogen in yellow, carbon in grey and oxygen in red; positive phases in green and negative phases in blue)

\section{CONCLUSIONS}

From NMR conformation analysis of 4',7-di-hydroxy-8prenylflavan 1 in acetone- $d 6$, DMSO- $d 6$, and $\mathrm{CDCl}_{3}$, and geometry optimizations (AM1 and DFT/BLYP/6-31G*), the three conformers $\mathbf{1 a}, \mathbf{1 b}$, and $\mathbf{1 c}$ were proposed. In all these conformers, ring $\mathrm{C}$ is in an equatorial position; however, they differ with respect to the spatial position of the prenyl group. The rotational barriers calculated for the prenyl group shows that the conformational interconversion between 1a and 1c is thermodynamically favored. However, NMR data are rather characteristic, indicating the absence of interconversion between these conformers. Thus, an effect of the solvent on the stability of each conformer can be proposed. This observation is in agreement with geometry optimization calculations of the systems constituted by $\mathbf{1 a}, \mathbf{1 b}$, and $\mathbf{1 c}$ with each of the solvents. The results confirm the existence of a preference of a given conformation for a certain solvent, $\mathbf{1 a}$ with acetone, $\mathbf{1 b}$ with $\mathrm{DMSO}$, and $\mathbf{1 c}$ with $\mathrm{CHCl}_{3}$.

Theoretical calculations demonstrated that the type of solutesolvent interaction depends on the type of solvent used, considering three different sites of the solute molecule for the approximation of the solvent molecule, namely, the prenyl group, A ring, or both jointly.

The interaction of 1a with acetone depends on the molecular site considered. Electrostatic interactions are observed when only the prenyl group is involved. However, electronic delocalization with the concomitant participation of the solute and the solvent is observed when only ring $\mathrm{A}$ is involved. The calculations demonstrate that the interaction of the prenyl group is more favored thermodynamically $\left(\Delta H_{\mathrm{i}}=-4.4 \mathrm{kcal} / \mathrm{mol}\right)$ than that of the A ring $\left(\Delta H_{\mathrm{i}}=-2.5 \mathrm{kcal} / \mathrm{mol}\right)$, or when the prenyl group and A ring are considered simultaneously $\left(\Delta H_{\mathrm{i}}=-3.2 \mathrm{kcal} / \mathrm{mol}\right)$. These results suggest that electrostatic interaction in the 1a-acetone system is more important than electronic delocalization. Therefore, since even smaller steric restrictions are expected for the approximation of the acetone molecule to the prenyl group in conformation 1a, an agreement between theoretical and NMR experimental results of $\mathbf{1}$ in acetone is observed.

In the case of the interaction of $\mathbf{1 b}$ with DMSO, the theoretical calculations demonstrate that there is only electronic delocalization in the solute-solvent system, regardless of the site of approximation considered, and that the interaction involving the prenyl group and the hydroxyl group of ring A is more favored thermodynamically $\left(\Delta H_{\mathrm{i}}=-3.7 \mathrm{kcal} / \mathrm{mol}\right)$ than isolated interactions with the prenyl group $\left(\Delta H_{\mathrm{i}}=-1.4 \mathrm{kcal} / \mathrm{mol}\right)$, and with ring A only $\left(\Delta H_{\mathrm{i}}=-2.0 \mathrm{kcal} / \mathrm{mol}\right)$. These data are in agreement with the conformation deduced from NMR experiments for $\mathbf{1 b}$, which presents a spatial arrangement that favors the simultaneous interaction of the prenyl group, the hydroxyl of the A ring, and the DMSO molecule.

For the interactions of $1 \mathrm{c}$ with $\mathrm{CHCl}_{3}$, the calculations demonstrate that, for any approximation site considered, the interactions have a predominantly electrostatic character, the concomitant interactions with the prenyl group and $\mathrm{A}$ ring $\left(\Delta H_{\mathrm{i}}=\right.$ $-1.5 \mathrm{kcal} / \mathrm{mol}$ ) being more favored than the interactions with ring $\mathrm{A}$ only $\left(\Delta H_{\mathrm{i}}=-1.4 \mathrm{kcal} / \mathrm{mol}\right)$ or with the prenyl group $\left(\Delta H_{\mathrm{i}}=-1.1\right.$ $\mathrm{kcal} / \mathrm{mol})$. These $\Delta H_{\mathrm{i}}$ data are in agreement with the conformation of 1c deduced from NOESY experiments, since the spatial arrangement of the substituents in ring A favors the approximation of the $\mathrm{CHCl}_{3}$ molecule concomitantly to this ring and the prenyl group.

Finally, as a result of the methodological sequence developed in this work, NMR analysis was shown to be a basic and very important instrument for the assessment the theoretical method of investigation of the chemical properties of flavan 1 .

\section{SUPPLEMENTARY MATERIAL}

Tables with all optimized geometrical parameters and other results for all structures considered in the present work are available from the authors upon request.

\section{ACKNOWLEDGEMENTS}

The authors thank the Conselho Nacional de Desenvolvimento Científico e Tecnológico (CNPq) and the Fundação Coordenação de Aperfeiçoamento de Pessoal de Nível Superior (CAPES) for financial support, and I. S. Lula and R. A. Machado for recording NMR spectra. The authors also thank the Prof. D. L. Nelson by the discussions about the text. 


\section{REFERENCES}

1. Walsaraj, R.; Pushpangadan, P.; Smitt, U. W.; Adsersen, A.; Christensen, S. B.; Sittie, A.; Nyman, U.; Nielsen, C.; Olsen, C. E.; J. Nat. Prod. 1997, $60,739$.

2. Nomura, T.; Fukay, T. In Progress in the Chemistry of Organic Natural Products; Herz, W.; Kirby, G. W.; Moore, R. E.; Steglic, W.; Tamm, C., eds.; Springer-Wien: New York, 1998, vol. 53, p. 51.

3. Pouget, C.; Fagnere, C.; Basly, J.-P.; Leveque, H.; Chulia, A.-J.; Tetrahedron 2000, 56, 6047.

4. Foo, L. Y.; Newman, R.; Waghorn, G.; McNabb, W. C.; Ulyatt, M. J.; Phytochemistry 1996, 41, 617.

5. Steynberg, P. J.; Steynberg, J. P.; Hemingway, R. W.; Ferreira, D.; McGraw, G. W.; J. Chem. Soc., Perkin Trans. 1 1997, 2395.

6. Rao, C. P.; Prashant, A.; Krupadanam, G. L. D.; Phytochemistry 1996, 41, 1223.

7. Passos, L. F. S.; Master Dissertation, Universidade Federal do Amazonas, Brazil, 1999.

8. Takashima, J.; Asano, S.; Ohsaki, A.; Planta Medica 2002, 68, 621.

9. Takashima, J.; Ohsaki, A.; J. Nat. Prod. 2001, 64, 1493.

10. Teixeira, A. F.; Alcântara, A. F. C.; Piló-Veloso, D.; Magn. Reson. Chem. 2000, 38, 301 .

11. Teixeira, A. F.; Master Dissertation, Universidade Federal do Amazonas, Brazil, 1999.

12. Silva, I. F.; Master Dissertation, Universidade Federal do Amazonas, Brazil, 2001.

13. See for example: Günther, H.; NMR Spectroscopy - Basic Principles, Concepts, and Applications in Chemistry, $2^{\text {nd }}$ ed., Wiley: Chichester, 1998, p. 335-389.

14. PC SPARTAN Plus; Tutorial and User's Guide; Wavefunction, Inc., USA, 1997; TITAN; Tutorial and User's Guide; Wavefunciton, Inc. \& Schrödinger, Inc., USA, 1999; Frisch, Æ.; Frisch, M. J.; Trucks, G. W.; Gaussian 03 User's Reference; Gaussian, Inc., USA, 2003.
15. Dewar, M. J. S.; Zoebish, E. G.; Healy, E. F.; Stewart, J. J. P.; J. Am. Chem. Soc. 1985, 107, 902.

16. Parr, R. G.; Yang, W.; Density Functional Theory of Atoms and Molecules, Oxford: New York, 1989.

17. Becke, A. D.; Phys. Rev. A: At., Mol., Opt. Phys. 1988, 38, 3098.

18. Lee, C.; Yang, W.; Parr, R. G.; Phys. Rev. B: Condens. Matter Mater. Phys. 1988, 37, 785 .

19. Frisch, M. J.; Trucks, G. W.; Schlegel, H. B.; Gill, P. M. W.; Johnson, B. G.; Wong, M. W.; Foresman, J. B.; Robb, M. A.; Head-Gordon, M.; Replogle, E. S.; Gomperts, R.; Andres, J. L.; Raghavachari, K.; Bincley, J. S.; Gonzales, C.; Martin, R. L.; Fox, D. J.; Defrees, D. J.; Baker, J.; Stewart, J. J. P.; Pople, J. A.; Gaussian 92/DFT Supplement Manual, Gaussian, Inc., USA, 1993.

20. Becke, A. D.; J. Chem. Phys. 1993, 98,1372

21. Becke, A. D.; J. Chem. Phys. 1993, 98, 5648

22. Stephens, P. J.; Devlin, F. J.; Cheeseman, J. R.; Frisch, M. J.; Rosini, C.; Org. Lett. 2002, 4, 4595.

23. Ditchfield, R.; Hehre, W. J.; Pople, J. A.; J. Chem. Phys. 1971, 54, 724.

24. Hehre, W. J.; Ditchfield, R.; Pople, J. A.; J. Chem. Phys. 1972, 56, 2257.

25. Hariharan, P. C.; Pople, J. A.; Mol. Phys. 1974, 27, 209.

26. Gordon, M. S.; Chem. Phys. Lett. 1980, 76, 163.

27. Hariharan, P. C.; Pople, J. A.; Theor. Chim. Acta 1973, 28, 213.

28. Cossi, M.; Barone, V.; Camimi, R.; Tomasi, J.; Chem. Phys. Lett. 1996, $255,327$.

29. Barone, V.; Cossi, M.; Tomasi, J.; J. Chem. Phys. 1997, 107, 3210.

30. Dos Santos, H. F.; De Almeida, W. B.; THEOCHEM 1995, 335, 129.

31. Isaacs, N.; Physical Organic Chemistry, Longman: Singapore, 1996, p. 3639.

32. Eliel, E. L.; Wilen, S. H.; Mander, L. N.; Stereochemistry of Organic Compounds, Wiley: New York, 1994, p. 643.

33. Maskill, H.; The Physical Basis of Organic Chemistry, Oxford: New York, 1993 , p. 17-35. 